This is the submitted version, later published in Polymer Chemistry (RSC). The reference of the final edited and published work is Polym. Chem., 2021, 12, 5963-5969 DOI: 10.1039/d1py01165k, and can be found at https://pubs.rsc.org/en/ content/articlelanding/2021/py/d1py01165k

\title{
ARTICLE
}

\section{Highly Efficient Vinylic Addition Polymerization of 5-Vinyl-2- Norbornene using Benzylic Palladium Complexes as Precatalysts}

Received 00th January 20xx, Accepted 00th January 20xx

DOI: $10.1039 / x 0 x x 00000 x$

\begin{abstract}
Ignacio Pérez-Ortega and Ana C. Albéniz*
In contrast with the parent norbornene, the vinylic addition polymerization of substituted norbornene derivatives is difficult to achieve. We have found that benzylic palladium complexes are suitable precatalysts in the challenging vinylic addition polymerization of 5-vinyl-2-norbornene (VNB). A mixture of $\left[\mathrm{Pd}_{2}(\mu-\mathrm{Br})_{2}\left(\eta^{3}-\mathrm{C}_{6} \mathrm{H}_{5} \mathrm{CHCH}_{2} \mathrm{C}_{6} \mathrm{~F}_{5}\right)_{2}\right](\mathbf{1}), \mathrm{PCy}_{3}$ and $\mathrm{NaBAr}{ }_{4}$ leads to a very active catalyst that homopolymerizes VNB leading to high molecular weight polymers where the exocyclic pendant double bond is preserved. Only $2 \mathrm{ppm}$ of palladium are needed to obtain VA-PVNB in high yield. The order of mixing of the components of the precatalyst mixture does not affect the degree of polymerization but it influences the initiation step which occurs by insertion of VNB: a) into a Pd-H bond generated from the neutral complex $\mathbf{1}$ or b) into a Pd$\mathrm{C}\left(\right.$ benzyl) bond when the cationic $\left[\mathrm{Pd}\left(\eta^{3}-\mathrm{C}_{6} \mathrm{H}_{5} \mathrm{CHCH}_{2} \mathrm{C}_{6} \mathrm{~F}_{5}\right)\left(\mathrm{PC} \mathrm{y}_{3}\right)(\mathrm{L})\right] \mathrm{BAr}{ }_{4}^{\mathrm{F}}$ is preformed. In either case, the easy transformation from $\eta^{3}$ - to a $\sigma$-benzyl opens a coordination site on the metal that favors the initiation. The nature of the counterion is important in the propagation of the polymerization and, among several low-coordinating anions tested, $\mathrm{BAr}_{4}^{-}$is the most efficient.
\end{abstract}

\section{Introduction}

The vinylic addition polymerization of norbornene attracts a lot of interest because of the robustness of the backbone of the resulting polymer (VA-PNB), formed by saturated bicyclic units (Scheme 1). This skeleton confers thermal and chemical stability and as well as high $\mathrm{T}_{\mathrm{g}} \mathrm{s}$ and transparency, which makes it suitable and attractive for many applications. ${ }^{1}$ One of the main drawbacks of the VA-polymerization of norbornene is the low tolerance of the existing catalysts to the presence of substituents in the monomer. ${ }^{2}$ As a result, the introduction of functional groups anchored to the main-polymer skeleton relies on the post-polymerization functionalization of a few types of suitable precursor VA-PNBs, such as $\omega$-bromoalkyl substituted VA-PNBs., ${ }^{3,4}$ Therefore, the discovery of new catalysts for the efficient VA-polymerization of norbornene derivatives is still a challenge.

Alkenyl norbornenes are attractive monomers for the VApolymerization of the norbornene moiety (Scheme 1). A pendant double bond, specially a terminal one, in a VA-PNB scaffold is a versatile functional group for easy transformation in other functional groups by addition reactions, oxygenation, etc. $^{5-8}$ 5-Vinyl-2-norbornene (VNB), easily accessible and commercially available, is a good candidate but very few catalytic systems are capable of homopolymerize VNB by a

IU CINQUIMA/Química Inorgánica. Universidad de Valladolid. 47071 Valladolid (Spain).

Electronic Supplementary Information (ESI) available: Experimental details, compound characterization, $\mathrm{X}$-ray structure determination data, and spectra (PDF) as well as crystallographic files (CIF). See DOI: 10.1039/x0xx00000x. vinylic addition route efficiently. Some catalysts used for the VA-polymerization of 5-vinyl-2-norbornene are not selective and besides the addition polymerization of the endocyclic double bond they also bring about the insertion of the exocyclic one, eliminating the pendant functionality. ${ }^{9}$ Besides the complications in chemoselectivity, the VA-polymerization of this diene has additional difficulties. VNB is a mixture of endo and exo isomers as a result of the Diels-Alder reaction involved in its synthesis. As for many other substituted norbornenes, the endo isomer (the major one) is the least reactive. ${ }^{10-12}$ Also, both endocyclic and exocyclic unsaturations in endo-VNB are perfectly arranged to coordinate to the metal in a chelating fashion, which could slow down the polymerization process. Even in a monodentate fashion the terminal double bond in VNB is a competing ligand. It is noteworthy that the isomeric 5-ethylidene-2-norbornene (ENB) showing an internal, less coordinating double bond undergoes an easier polymerization and very active catalysts have been recently reported for the VA-homopolymerization of ENB. ${ }^{13-15}$

The most active catalytic mixture for the homopolymerization of VNB was described by Wakatsuki et al. ${ }^{16}$ They used the mixture represented in Scheme 1 and obtained good yields of high molecular weight VA-PVNB with an amount of palladium catalyst as low as $0.02 \mathrm{~mol} \%$. Bermeshev et al. have used a $\mathrm{Pd}(\mathrm{II})$-N-heterocyclic carbene complex as palladium source with similar results. ${ }^{13}$ This activity is far from that reached with the same system for ENB (efficient polymerization in high yield using an amount of catalyst of $10^{-4} \mathrm{~mol} \%$ ). Claverie used the mixture $\mathrm{Pd}_{2}(\mathrm{dba})_{3}: \mathrm{AgSbF}_{6}: \mathrm{PPh}_{3}(0.02 \mathrm{~mol} \%$ of $\mathrm{Pd})$ to obtain a 


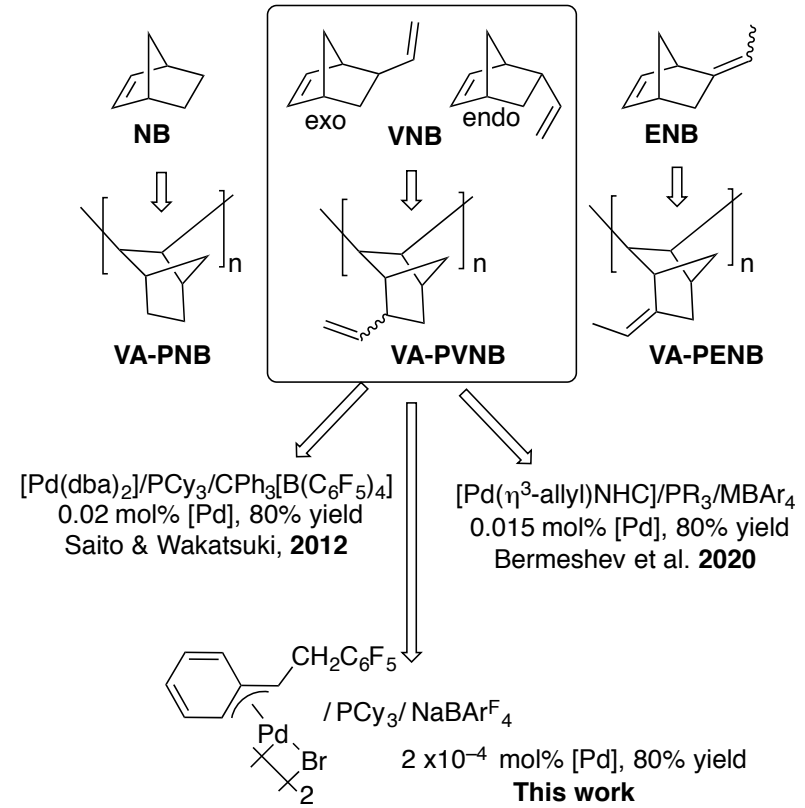

Scheme 1. Vinylic addition polymers of norbornene (NB), 5-ethylidene-2-norbornene (ENB) and 5-vinyl-2-norbornene (VNB) showing the precedent catalytic systems for the latter.

low molecular weight VA-PVNB. ${ }^{7}$ Other reported precatalytic mixtures showed less efficiency, or led to oligomers. ${ }^{7,17}$ VAcopolymers of VNB with norbornene have also been synthesized using palladium or nickel catalysts with low incorporation of $\mathrm{VNB}^{18}$ The use of certain zirconocene derivatives allows to co-polymerize VNB and ethylene or propylene without the involvement of the exocyclic double bond of VNB; however the incorporation of VNB in the copolymers is low. ${ }^{19-21}$

The efficient polymerization of norbornene with palladium complexes is usually accomplished using cationic species with easily available coordination sites on the metal. In this way, the coordination of the olefin and the subsequent insertion into the $\mathrm{Pd}-\mathrm{C}$ bond are favored. We have been working for some time with $\eta^{3}$-benzylic palladium complexes and studying their structure and reactivity. ${ }^{22,23}$ We rationalized that in the context of the vinylic addition (VA) polymerization of norbornenes these complexes might be ideal precursors since the $\eta^{3}$-benzyl moiety can easily interconvert into the $\sigma$-benzyl form, leaving a coordination site available and facilitating the subsequent initiation by coordination and insertion of NB. Because of the easy transformation into the $\sigma$-benzyl, driven by the recovery of the aromaticity of the ring, these complexes might be superior precatalysts than the more commonly used $\eta^{3}$-allyl palladium complexes (Scheme 2 ). It has been shown that the terminal double bond of the allyl fragment can coordinate after the first insertion of norbornene, slowing down the initiation step of the polymerization. ${ }^{24,25}$ This chelating organometallic fragment would not be formed from a palladium benzyl (Scheme 2). Only one example of the polymerization of norbornene with a benzylic precursor of nickel has been reported in the literature. ${ }^{26}$

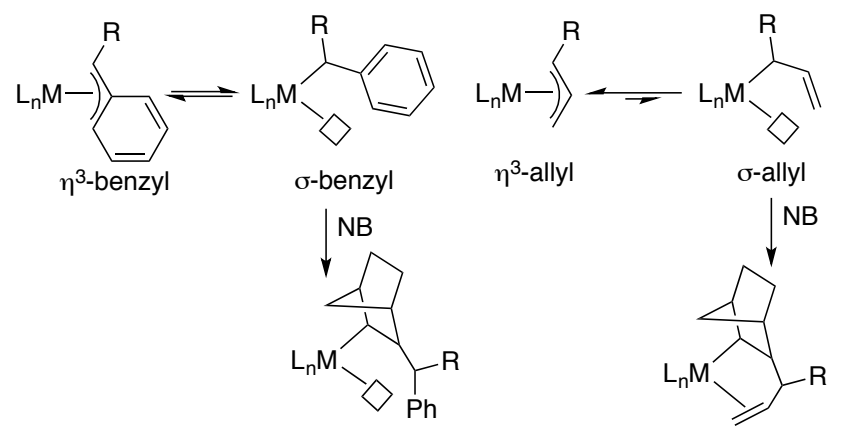

Scheme 2. $\sigma-\eta^{3}$ interconversion for benzylic and allyllic complexes and reaction with NB.

We describe here the use of an $\alpha$-substituted benzylic palladium complex as precatalyst in the challenging homopolymerization of 5-vinyl-2-norbornene (VNB). The complex generates very active species capable of polymerizing VNB in high yields affording high molecular weight polymers (VA-PVNB) with, to our knowledge, the lowest amount of catalyst reported to date. We have studied in detail the species involved in the initiation of the polymerization of this new type of palladium precatalyst.

\section{Results and discussion}

$\left[\mathrm{Pd}(\mu-\mathrm{Br})\left(\eta^{3}-\mathrm{C}_{6} \mathrm{H}_{5} \mathrm{CHCH}_{2} \mathrm{C}_{6} \mathrm{~F}_{5}\right)\right]_{2}(\mathbf{1})$ is an $\alpha$-substituted benzylic derivative that can be easily prepared by insertion of styrene into the $\mathrm{Pd}-\mathrm{C}_{6} \mathrm{~F}_{5}$ bond of a suitable precursor in good yields (see $\mathrm{SI}$ ). It can be handled with no special precautions since it is moisture and air stable and can be stored for long periods of time at $-15^{\circ} \mathrm{C}$. The neutral benzyl $\mathbf{1}$ is not active in the vinylic addition polymerization of norbornene so we tested cationic derivatives, synthesized from $\mathbf{1}$, in the homopolymerization of 5-vinyl 2-norbornene (VNB). We used commercial VNB which is a mixture of endo:exo isomers in a 80:20 ratio. The isolated complexes $\left[\mathrm{Pd}\left(\eta^{3}-\mathrm{C}_{6} \mathrm{H}_{5} \mathrm{CHCH}_{2} \mathrm{C}_{6} \mathrm{~F}_{5}\right)\left(\mathrm{PPh}_{3}\right)_{2}\right] \mathrm{X}\left(\mathrm{X}=\mathrm{BF}_{4}, \mathrm{BAr}_{4}{ }_{4}\right)^{22}$ do not polymerize VNB. However, analogous cationic species with a lower amount of phosphine generated in situ from a mixture of $1 / \mathrm{PPh}_{3} / \mathrm{NaBAr}_{4}{ }_{4}$ (ratio Pd: $\mathrm{PPh}_{3}: \mathrm{BAr}_{4}{ }^{-}=1: 1: 1$ ) led to a polymer in $65 \%$ yield (entry 1 , Table 1 ). A short screening of phosphines revealed that tricyclohexylphosphine leads to the most active species and almost complete conversion was observed in the polymerization of VNB in $5 \mathrm{~h}$ (entries 1-5, Table 1). The lower activity of $\mathrm{P}^{\mathrm{t}} \mathrm{Bu}_{3}$ when compared to $\mathrm{PC} \mathrm{y}_{3}$, could be related to its larger size but also to its ability to undergo metalation processes which could open catalyst deactivation pathways. ${ }^{27}$ Besides $\mathrm{NaBAr}_{4}{ }_{4}$, other halogen scavengers were tested. The polymerization is more effective for the larger, less coordinating anions and the yield increases in the order: $\mathrm{BAr}_{4}{ }^{-}>\mathrm{SbF}_{6}{ }^{-}>\mathrm{BF}_{4}{ }^{-}$(entries 5, 6 and 8, Table 1). As we will discuss below the counterion does not influence the initiation step but rather the propagation of the polymerization. The similar results obtained for $\mathrm{AgBF}_{4}$ and $\mathrm{TlBF}_{4}$ rules out that silver is acting as a phosphine scavenger and favoring the decomposition of naked catalyst species. 
Table 1. Effect of the phosphine and the anion in the polymerization of VNB with the precatalyst mixture $1 / \mathrm{PR}_{3} / \mathrm{MBX}_{4}{ }^{\text {a }}$

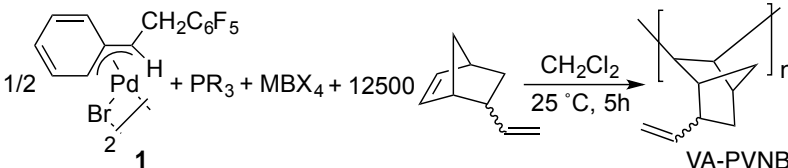

\begin{tabular}{cccccc}
\hline Entry & Phosphine & $\mathrm{MBR}_{4}$ & Yield (\%) & $\mathrm{M}_{\mathrm{w}}\left(\times 10^{-3}\right)^{\mathrm{b}}$ & $\mathrm{PDI}^{\mathrm{b}}$ \\
\hline 1 & $\mathrm{PPh}_{3}$ & $\mathrm{NaBAr}_{4}{ }_{4}$ & $65 \%$ & 284.3 & 2.9 \\
2 & $\mathrm{P}(\text { o-tolyl })_{3}$ & $\mathrm{NaBAr}_{4}{ }_{4}$ & $35 \%$ & 69.6 & 2.3 \\
3 & $\mathrm{P}\left(\mathrm{C}_{6} \mathrm{~F}_{5}\right)_{3}$ & $\mathrm{NaBAr}_{4}{ }_{4}$ & $5 \%$ & 17.01 & 1.6 \\
4 & $\mathrm{P}^{t} \mathrm{Bu}_{3}$ & $\mathrm{NaBAr}_{4}^{\mathrm{F}}$ & $37 \%$ & 310.2 & 2.9 \\
5 & $\mathrm{PCy}_{3}$ & $\mathrm{NaBAr}_{4}$ & $95 \%$ & 1165.8 & 3.1 \\
6 & $\mathrm{PCy}_{3}$ & $\mathrm{AgBF}_{4}$ & $20 \%$ & 469.8 & 2.6 \\
7 & $\mathrm{PCy}_{3}$ & $\mathrm{TIBF}_{4}$ & $23 \%$ & n.d. & n.d \\
8 & $\mathrm{PCy}_{3}$ & $\mathrm{AgSbF}_{6}$ & $62 \%$ & 955.8 & 3.3
\end{tabular}

a Reaction conditions: $\mathrm{CH}_{2} \mathrm{Cl}_{2},[\mathrm{VNB}]_{\circ}=3.8 \mathrm{M},[\mathrm{Pd}]=3 \times 10^{-4} \mathrm{M}, 25 \stackrel{\circ}{\circ}, 5 \mathrm{~h}$, ratio VNB:Pd $=12.500: 1,1$ equivalent of phosphine and $\mathrm{NaBAr}_{4}{ }_{4}$ per palladium. ${ }^{b}$ Determined by GPC in $\mathrm{CHCl}_{3}$ using polystyrene standards; $\mathrm{M}_{\mathrm{w}}$ in Da.

The polymers obtained, VA-PVNBs, show the typical broad signals of vinylic addition polynorbornenes in the NMR spectra, reflecting their complicated morphology and large size. Only the endocyclic double bond is involved in the polymerization of VNB and the chemical shifts of the olefinic signals in the ${ }^{1} \mathrm{H}$ NMR of the polymers indicate the presence of just the terminal double bond. The intensity of the alkene signals vs the aliphatic region is also consistent with the vinyl group not participating in the polymerization (Fig. 1). Both the endo and exo alkenyl arrangements, present in the monomer, can be observed in the ${ }^{13} \mathrm{C}$ NMR of the VA-PVNBs, as well as the

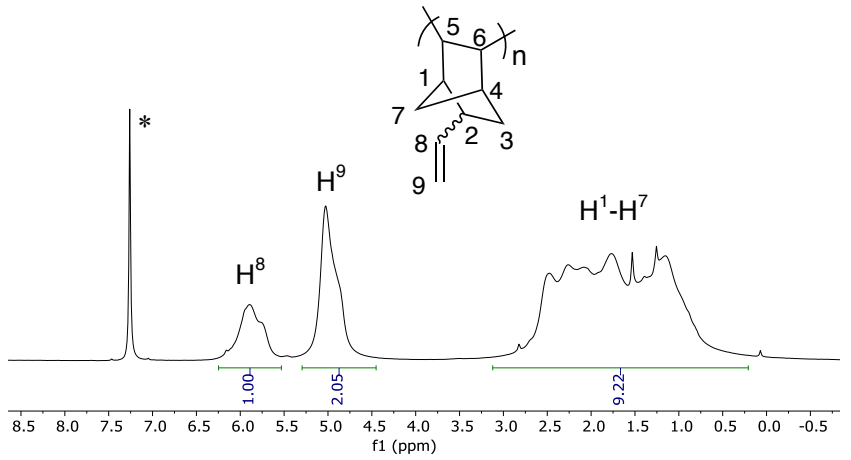

Fig. 1. ${ }^{1} \mathrm{H}$ NMR $\left(500.13 \mathrm{MHz}, \mathrm{CDCl}_{3}\right)$ of the polymer VA-PVNB (entry 9, Table 2). ${ }^{*} \mathrm{CHCl}_{3}$.

absence of signals around $20 \mathrm{ppm}$ indicative of a 2,3-exo enchained backbone (see ESI). The experiment in entry 5 , Table 1, shows that this precatalyst mixture leads to a more active catalyst than those previously reported for the polymerization of VNB (maximum ratio used in the literature VNB:Pd $=7000: 1)$. We decided to probe further the activity of the mixture $1 / \mathrm{PCy}_{3} / \mathrm{NaBAr}_{4}{ }_{4}$ and Table 2 shows the polymerization results using a low amount of $\mathrm{Pd}(\leq 20 \mathrm{ppm})$. For a ratio $\mathrm{Pd}: \mathrm{VNB}=1: 50000(20 \mathrm{ppm}$ of $\mathrm{Pd})$ at room temperature, only $39 \%$ yield was obtained. The conversion does not increase significantly by adding an excess of $\mathrm{NaBAr}_{4}{ }_{4}$ or an additional equivalent of $\mathrm{PCy}_{3}$ (entries 1-3, Table 2). However an increase of the temperature to $45{ }^{\circ} \mathrm{C}$ leads to an efficient polymerization using as low an amount of catalyst as $10 \mathrm{ppm}$ of Pd (entry 6, Table 2). The polymerization can be carried out at $75^{\circ} \mathrm{C}$ in 1,2-dichloroethane and good yields of VA-PVNB can be obtained with a concomitant increase of the VNB and catalyst concentration. Under these conditions the polymerization can be carried out in $78 \%$ yield using just 2 ppm of Pd (entry 11, Table 2).

Table 2. Polymerization of VNB with the system $1 / \mathrm{PC}_{3} / \mathrm{NaBAr}_{4 .}^{\mathrm{F}}{ }^{\mathrm{a}}$

\begin{tabular}{cccccccc}
\hline Entry & $\mathrm{T}\left({ }^{\circ} \mathrm{C}\right)$ & VNB:Pd & Solvent & time & Yield (\%) & $\mathrm{M}_{\mathrm{w}}{ }^{\mathrm{b}}$ & PDI $^{\mathrm{b}}$ \\
\hline 1 & 25 & $50000: 1$ & $\mathrm{CH}_{2} \mathrm{Cl}_{2}$ & $5 \mathrm{~h}$ & $39 \%$ & 1070656 & 3.1 \\
$2^{\mathrm{c}}$ & 25 & $50000: 1$ & $\mathrm{CH}_{2} \mathrm{Cl}_{2}$ & $5 \mathrm{~h}$ & $47 \%$ & 1127977 & 2.9 \\
$3^{\mathrm{d}}$ & 25 & $50000: 1$ & $\mathrm{CH}_{2} \mathrm{Cl}_{2}$ & $5 \mathrm{~h}$ & $40 \%$ & 1057805 & 2.7 \\
$4^{\mathrm{e}}$ & 25 & $50000: 1$ & $\mathrm{CH}_{2} \mathrm{Cl}_{2}$ & $5 \mathrm{~h}$ & $45 \%$ & 987021 & 3.3 \\
$5^{\mathrm{f}}$ & 25 & $50000: 1$ & $\mathrm{CH}_{2} \mathrm{Cl}_{2}$ & $5 \mathrm{~h}$ & $39 \%$ & 1023283 & 3.4 \\
6 & 45 & $50000: 1$ & $\mathrm{CH}_{2} \mathrm{Cl}_{2}$ & $5 \mathrm{~h}$ & $92 \%$ & 998789 & 3.1 \\
7 & 45 & $100000: 1$ & $\mathrm{CH}_{2} \mathrm{Cl}_{2}$ & $5 \mathrm{~h}$ & $80 \%$ & 1016062 & 3.2 \\
8 & 75 & $100000: 1$ & 1,2 -dichloroethane & $2 \mathrm{~h}$ & $94 \%$ & 839270 & 3.3 \\
9 & 75 & $500000: 1$ & 1 1,2-dichloroethane & $12 \mathrm{~h}$ & $55 \%$ & 868339 & 3 \\
10 & 75 & $2000000: 1$ & 1,2-dichloroethane & $3 \mathrm{~h}$ & $40 \%$ & 677527 & 3.8 \\
$11^{\mathrm{g}}$ & 75 & $500000: 1$ & 1,2-dichloroethane & $3 \mathrm{~h}$ & $78 \%$ & 728005 & 3.2 \\
$12^{\mathrm{h}}$ & 75 & $500000: 1$ & 1,2-dichloroethane & $20 \mathrm{~min}$ & $80 \%$ & 500024 & 3.7
\end{tabular}

${ }^{a}$ Reaction conditions: $\mathrm{Pd}: \mathrm{PCy}_{3}: \mathrm{NaBAr}_{4}{ }_{4}=1: 1: 1$ mol ratio, $[\mathrm{VNB}]_{0}=3.8 \mathrm{M}$, VNB and 1 were mixed followed by the addition of $\mathrm{PC} \mathrm{y}_{3}$ and $\mathrm{NaBAr}_{4}{ }_{4}$ unless otherwise noted. ${ }^{\mathrm{b}}$

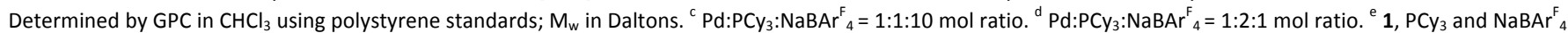
were mixed followed by the addition of VNB. ${ }^{f}$ Complex $4-B A r^{\mathrm{F}}{ }_{4}$ was used as precatalyst. ${ }^{\mathrm{g}}[\mathrm{VNB}]_{\mathrm{o}}=6.8 \mathrm{M} .{ }^{\mathrm{h}} \mathrm{ENB}$ instead VNB; $[\mathrm{ENB}]_{0}=6.8 \mathrm{M}$. 
The system is also useful for the polymerization of the more active monomer 5-ethylidene-2-norbornene (ENB, entry 12, Table 2). Other solvents or solvent mixtures were also tested but the chlorinated solvents proved to be superior (see ESI). Mixtures $[\mathrm{PdCIMeL}]_{n} / \mathrm{NaBAr}_{4}{ }_{4}\left(\mathrm{~L}=\mathrm{P}^{\mathrm{t}} \mathrm{Bu}_{3}, \mathrm{n}=1 ; \mathrm{L}=\mathrm{PCy}_{3}, \mathrm{n}=2\right)$ were also tested for comparison, but the methyl precatalysts showed a poorer performance (see ESI).

As shown in Tables 1 and 2, the VA-PNBs obtained are quite polydisperse (PDI values around 3 ) and show high $M_{w}$, as determined by GPC using polystyrene standards, close to $10^{6}$ Da for the $1 / \mathrm{PCy}_{3} / \mathrm{NaBAr}_{4}{ }_{4}$ precatalyst mixture. This was also checked by determining the viscosity of two high molecular weight polymer samples obtained for different VNB:Pd ratios (entry 5, Table 1 and entry 6, Table 2), which showed the same value (inherent viscosity $=4$ for solutions of concentration 0.5 g/dL). Fig. 2 shows a plot of the molecular weight $\left(M_{n}\right)$ of the VA-PVNBs vs conversion using the same monomer/catalyst ratio (VNB:Pd = 12500:1, see ESI for details). A steady increase of molecular weight with conversion is observed at low yields but as the reaction progresses the growth of the polymer slows down and the size of the VA-PVNB reaches a maximum. This, along with the high polydispersity indicates that the polymerization is not living and a termination mechanism starts to dominate over the propagation when the polymer reaches a large size. Since the polymerization yield still increases without a concomitant increase of average polymer size, it means that the termination leads to palladium active species capable of producing new polymer chains till the initial monomer is almost consumed. The result is a highly active polymerization system that allows to synthesize high molecular weight VA-PVNBs (around 5-10 ×10 $5 \mathrm{Da}$ ).

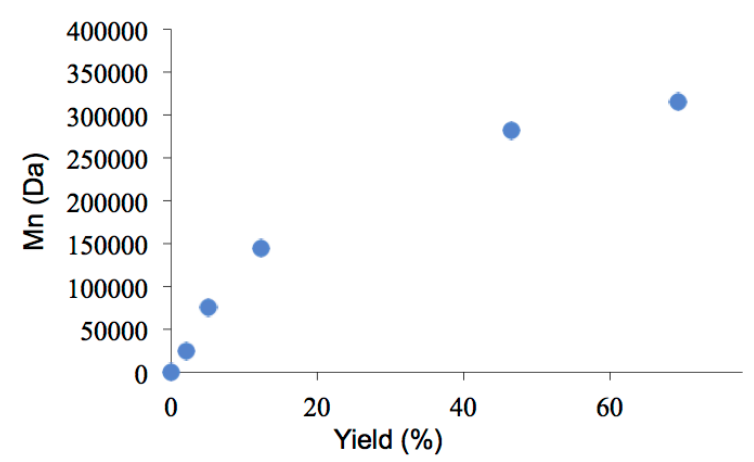

Fig. 2. Plot of the VA-PVNB molecular weight $\left(M_{n}\right)$ vs yield (initial mol ratio VNB:Pd = 12500:1).

In order to find out about the species involved in the initiation of the polymerization, the reactions of complex 1 with $\mathrm{PCy}_{3}$ and the bromide scavenger $\mathrm{NaBAr}_{4}{ }_{4}$ were explored. The formation of the monomeric complex 2 occurs when one equivalent of $\mathrm{PCy}_{3}$ per palladium reacts with 1 (Scheme 3).

Complex $\mathbf{2}$ is a $\eta^{3}$-benzylic derivative, as shown by the characteristic chemical shift of $\mathrm{C}^{\alpha}$ at $53 \mathrm{ppm},{ }^{22}$ and it is stable only at very low temperature. As it is observed for most benzylic phosphine complexes described here, $\mathbf{2}$ undergoes a fast syn-anti interconversion in solution even at $195 \mathrm{~K}$ probably via a suprafacial sigmatropic rearrangement (see ESI for details). Complex $\mathbf{2}$ does not coordinate an additional molecule of the bulky $\mathrm{PCy}_{3}$ (Fig. S1). When 2 was treated with $\mathrm{NaBAr}_{4}{ }_{4}$ in $\mathrm{CD}_{2} \mathrm{Cl}_{2}$ a mixture of complexes was formed in solution at low $\mathrm{T}$, which undergo a fast exchange as the temperature is raised (Fig. S2 and S3). At $243 \mathrm{~K}$, two species were present and the NMR spectra of this solution are consistent with a mixture of $\eta^{3}$-benzylic species ( $C^{\alpha}$ at $54 \mathrm{ppm}$, in the ${ }^{13} \mathrm{C}$ NMR spectrum). These species can be depicted as $\mathbf{3}$ and the empty coordination site represented in Scheme 3 could be as such, or it could be a solvent molecule or adventitious water. Different stereoisomers are also possible for any composition. The addition of a small amount of acetonitrile (Pd:NCMe $=1: 4 \mathrm{~mol}$ ratio) led to the clean and complete transformation of the mixture into complex $4-\mathrm{BAr}_{4}{ }_{4}$, which supports the formulation of $\mathbf{3}$ as a mixture of $\eta^{3}$-benzylic isomers or derivatives with weakly coordinated ligands (Scheme 3 and Fig. S4 and S5). 4$\mathrm{BAr}_{4}{ }_{4}$ was isolated and its molecular structure is shown in Fig. 3 , a. The analogous complex $4-\mathrm{BF}_{4}$ was also prepared and crystallographically characterized (Fig. 3, b). Both complexes show the same cation structure: an anti benzylic fragment $\eta^{3}$ coordinated to palladium and a cis- $\mathrm{PCy}_{3}-\mathrm{C}^{\alpha}$ arrangement.

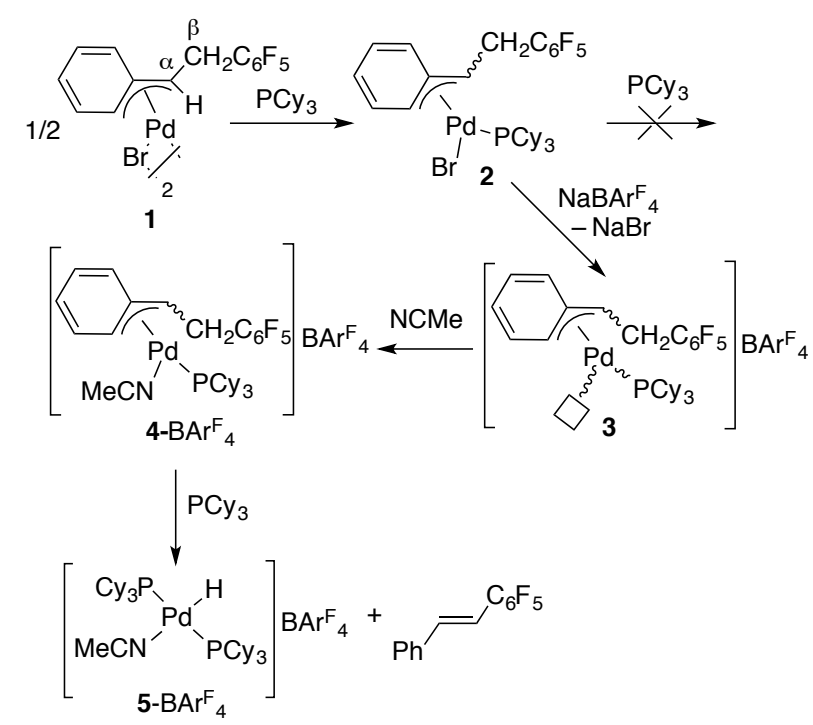

Scheme 3. Reactions of complex 1 with $\mathrm{PC}_{3}$ and $\mathrm{NaBAr}_{4}{ }_{4}$. 
a)

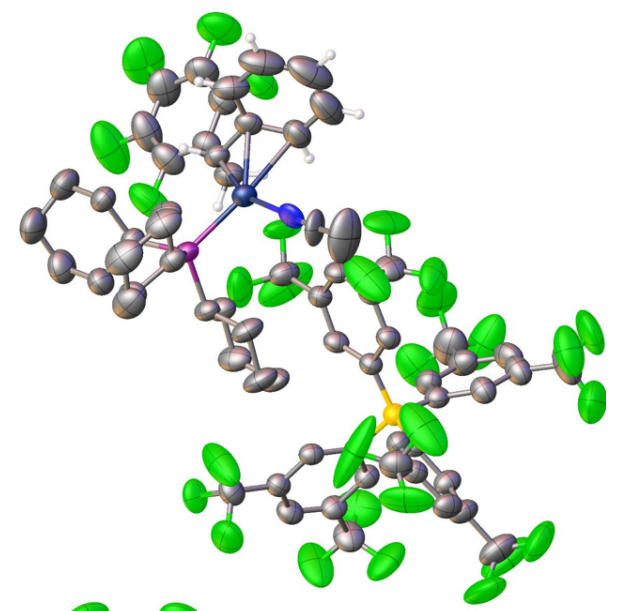

b)

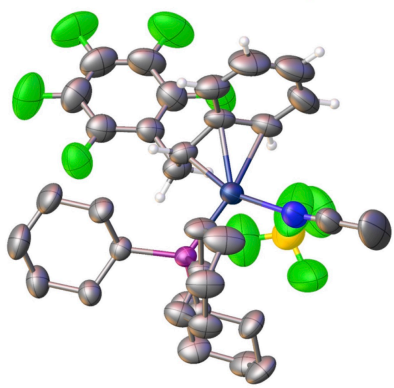

Fig. 3. Molecular structures of $4-\mathrm{BAr}_{4}^{\mathrm{F}}$ (a) and $4-\mathrm{BF}_{4}$ (b). ORTEP plots ( $50 \%$ probability) are shown. Some of the hydrogen atoms are omitted for clarity.

As expected, the $\mathrm{Pd}-\mathrm{C}$ distances show a $\mathrm{Pd}-\mathrm{C}^{\alpha}$ bond length (2.049(4), 4-BAr ${ }_{4}$ and 2.059(5), 4-BF 4 ) shorter than the $\mathrm{Pd}$ $C$ (aryl) bond distances (Pd- $C_{\text {ipso }} 2.215(4)$ and 2.206(5); Pd- $C_{\text {ortho }}$ 2.441(6) and 2.404(6) for 4-BAr ${ }_{4}{ }_{4}$ and $4-\mathrm{BF}_{4}$ respectively).

The addition of $\mathrm{PCy}_{3}$ to complex $4-\mathrm{BAr}_{4}^{\mathrm{F}}$ does not lead to the formation of a cis-diphosphino $\eta^{3}$-benzylic complex but to the decomposition of $4-\mathrm{BAr}_{4}{ }_{4}$ by $\beta-\mathrm{H}$ elimination leading to trans$\left[\mathrm{PdH}(\mathrm{NCMe})\left(\mathrm{PCy}_{3}\right)_{2}\right] \mathrm{BAr}_{4}{ }_{4}\left(5-\mathrm{BAr}_{4}^{\mathrm{F}}, \mathrm{Pd}-\mathrm{H}\right.$ at $-15.2 \mathrm{ppm},{ }^{2} \mathrm{~J}_{\mathrm{P}-\mathrm{H}}=$ $6.7 \mathrm{~Hz}$ ). The same behavior was observed for the tetrafluoroborate analogue and the hydride $\mathbf{5}-\mathrm{BF}_{4}$ was detected (see ESI).

Both the mixture $1 / \mathrm{PCy}_{3} / \mathrm{NaBAr}_{4}{ }_{4}$, independently of the order of mixing of the components, and complex $4-\mathrm{BAr}_{4}{ }_{4}$ have the same catalytic activity in the VA-polymerization of VNB (cf. entries 1, 4 and 5, Table 2). However, the initiation step showed interesting differences. The VA-polymerization of VNB can be carried out by mixing complex 1 and the monomer, followed by the addition of $\mathrm{PCy}_{3}$ and $\mathrm{NaBAr}_{4}{ }_{4}$ (A in Scheme 4). This is the method used in the most of the experiments collected in Tables 1 and 2. A follow up of the reaction by ${ }^{19} \mathrm{~F}$ NMR shows that upon addition of VNB to the neutral complex 1 a fast and complete $\beta-\mathrm{H}$ elimination occurs on the benzyl moiety leading to pentafluorostilbene and a putative palladium hydride that undergoes insertion of VNB into the Pd$\mathrm{H}$ bond (Fig. S8). No polymer was observed unless $\mathrm{PCy}_{3}$ and $\mathrm{NaBAr}_{4}{ }_{4}$ are added leading to a VA-PVNB with no fluorinated end groups. If $1, \mathrm{PCY}_{3}$ and $\mathrm{NaBAr}_{4}{ }_{4}$ are mixed, generating the mixture 3 (Scheme 3 ), before the addition of the monomer ( $B$, Scheme 4), the initiation occurs mostly by insertion of VNB into the $\mathrm{Pd}-\mathrm{C}($ benzyl) bond leading to polymers that contain

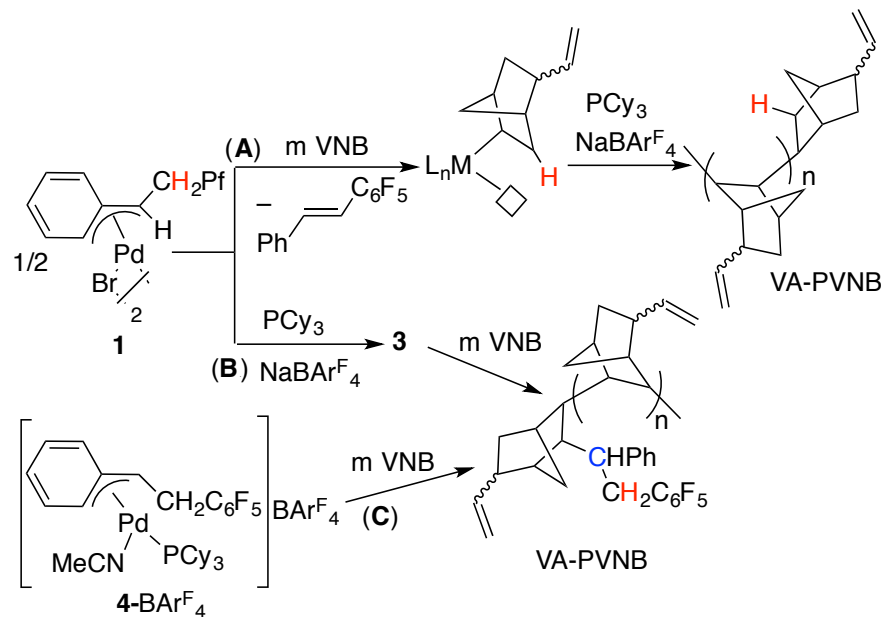

Scheme 4. Initiation reactions for the system $1 / \mathrm{PCy}_{3} / \mathrm{NaBAr}_{4}^{\mathrm{F}}$ and $\mathrm{VNB}$.

the fluorinated benzyl group in their structure (broad signals in ${ }^{19} \mathrm{~F}$ NMR corresponding to the $\mathrm{C}_{6} \mathrm{~F}_{5}$ group at -142.5 ( $\left.\mathrm{F}_{\text {ortho }}\right)$, $158\left(F_{\text {para }}\right),-163\left(F_{\text {meta }}\right)$, Fig. $\left.S 56\right)$. The same outcome is observed when the isolated $4-\mathrm{BAr}^{\mathrm{F}}{ }_{4}$ was used as precatalyst (C, Scheme 4). Only about $5-10 \%$ of the palladium benzylic moiety in reaction routes $\mathbf{B}$ and $\mathbf{C}$ (Scheme 4) decomposes by $\beta-\mathrm{H}$ elimination, and this can be quantified by the amount of pentafluorostilbene formed. This shows that, in contrast to the neutral complex 1, the insertion of VNB into the Pd-C bond of the cationic more electrophilic palladium complexes is faster that the $\beta-\mathrm{H}$ elimination. This behavior in the initiation step is also consistent with the high activity of the cationic species in the propagation of the polymerization where multiple insertions into the $\mathrm{Pd}-\mathrm{C}$ bond of the growing polymer are required. It is noteworthy that at low VNB:Pd ratio and short reaction times the insertion of $\mathrm{VNB}$ into the $\mathrm{Pd}-\mathrm{C}$ (benzyl) leads to two different sets of $\mathrm{C}_{6} \mathrm{~F}_{5}$ resonances in the ${ }^{19} \mathrm{~F} N \mathrm{NMR}$. Besides the broad pentafluorophenyl resonances attached to the polymer as mentioned above, other $\mathrm{C}_{6} \mathrm{~F}_{5}$-containing species are formed that evolve to the final VA-PVNB (Fig. 4 a, b). We could not characterized these species but their transformation to the final polymer with fluorinated end groups seems to indicate that they are organometallic species formed after one or several VNB insertions that undergo slow chain growth. These species are not observed when a higher VNB:Pd ratio is used (Fig. 4, c). These observations indicate that the initiation is not fast enough to provide a controlled polymerization and it is consistent with the polydispersity values observed.

Complex 4-BF 4 reacts with VNB in the same way described above for $4-\mathrm{BAr}_{4}{ }_{4}$ and the insertion of VNB into the Pd$C$ (benzyl) bond was observed (see Fig. S13 and S14). Therefore, the counterion has no significant influence in the initiation of the polymerization. However $4-\mathrm{BF}_{4}$ leads to less active species and the polymerization with this complex in the conditions of entry 5, Table 1 led to a VA-PVNB in only 19\% yield. The influence of the anion was also patent in the results of Table 1 (cf. entries 5-8). 

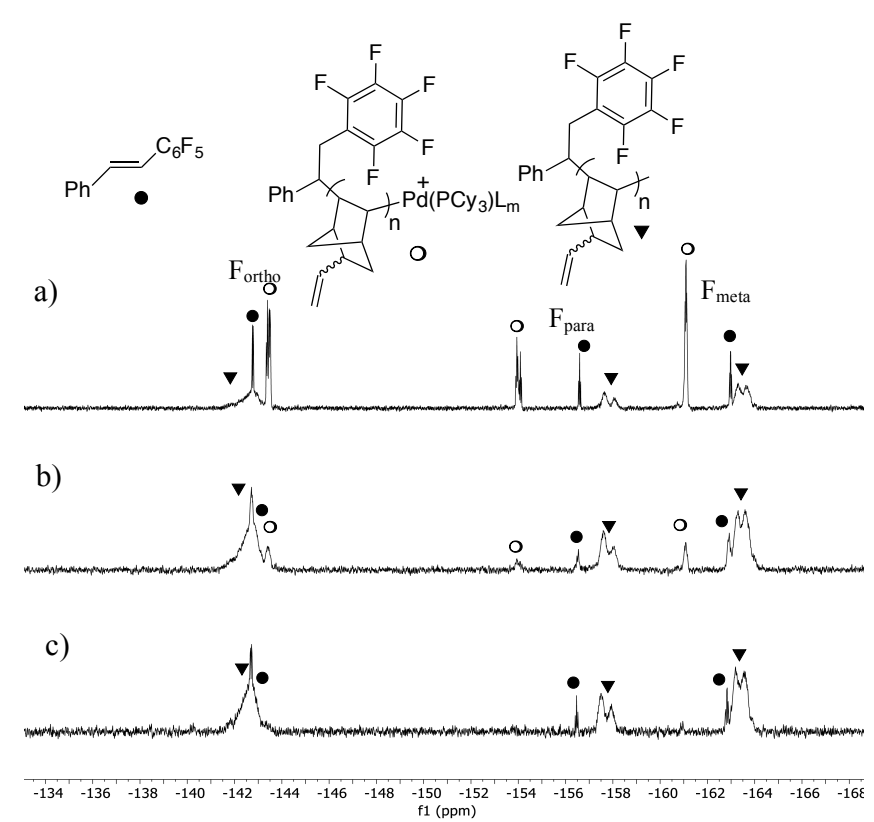

Fig. 4. Reaction of complex 4-BAr ${ }_{4}^{\mathrm{F}}$ with 5-vinyl-2-norbornene: a) mol ratio VNB:Pd = 125:1 after $15 \mathrm{~min}$; b) sample a after $3 \mathrm{~h}$; c) mol ratio VNB:Pd = 1000:1 after $15 \mathrm{~min}$.

The beneficial effect of large non-coordinating anions in metalcatalyzed polymerization reactions is known and it has been studied mostly in the context of group 4 metal catalyzed olefin polymerization, ${ }^{28,29}$ but also in palladium catalyzed processes. $^{30-32}$ The association of the counterion to the cationic complex is important since it can hinder the access of the monomer to the metal. Looking at the molecular structures of $4-\mathrm{BAr}_{4}{ }_{4}$ and $4-\mathrm{BF}_{4}$, it can be clearly seen how the bulky $\mathrm{BAr}_{4}{ }_{4}^{-}$is far form the palladium center whereas the small $\mathrm{BF}_{4}{ }^{-}$is placed on top of the palladium coordination plane, not too far from the metal (Fig. 3, b and Fig. S16; Pd...FBF $3.35 \AA$ average for the closest F). Although in solution the situation will be different, the solvents used in the polymerization $\left(\mathrm{CH}_{2} \mathrm{Cl}_{2}\right.$ and dichloroethane) do not exclude cation-anion pairing, which, in the case of $\mathrm{BF}_{4}^{-}$, could make the monomer coordination more difficult and therefore slow down the polymer growth.

The plausible active species in the propagation of the polymerization is a cationic monophosphino palladium complex $\left[\mathrm{Pd}(\mathrm{alkyl})\left(\mathrm{PCy}_{3}\right) \mathrm{L}_{\mathrm{m}}\right] \mathrm{BAr}_{4}{ }_{4}$ where $\mathrm{L}=\mathrm{VNB}$ and alkyl $=$ growing polymer. This is supported by the influence of the anion, which points to a cationic complex. Moreover, the observed reluctant coordination of a second $\mathrm{PCy}_{3}$ to palladium (Scheme 3) and the little influence in the polymerization of an excess of $\mathrm{PCy}_{3}$ (entries 1, 3, Table 2) supports a monophosphino species. The initiation of the polymerization, either via insertion into a $\mathrm{Pd}-\mathrm{H}$ or a $\mathrm{Pd}-\mathrm{C}$ bond, has no influence in the final polymer yield and size. The high molecular weight of the polymers and the presence of the vinyl group did not allow to identify any terminal group that could give information about the chain transfer mechanism of the polymerization. The involvement of the terminal double bond in the termination step of the VA-oligomerization of VNB has been proposed before. ${ }^{9}$ If, eventually, the insertion of a terminal double bond into the $\mathrm{Pd}-\mathrm{C}(\mathrm{Pol})$ bond takes place, a $\beta$ $\mathrm{H}$ elimination in the new Pd-alkyl formed could occur leading to an olefin terminated polymer chain and a Pd-hydride that could re-enter the polymerization catalytic cycle. This could also be operating here since, as mentioned before, when the molecular weight of the obtained polymers are compared with the initial VNB:Pd ratio and the yield, it is clear that much larger polymer chains could in principle be obtained. Therefore, each palladium center must be involved in the growth of more than one polymer chain.

\section{Conclusions}

A very efficient palladium catalyst for the polymerization of the reluctant 5-vinyl-2-norbornene (VNB) has been developed. The active species is a cationic palladium complex with a coordinated $\mathrm{PCY}_{3}$ and a non-coordinating counterion, i.e, $\left[\mathrm{Pd}\left(\right.\right.$ alkyl) $\left.\left(\mathrm{PC}_{3}\right) \mathrm{L}_{\mathrm{m}}\right] \mathrm{BAr}_{4}{ }_{4}$ (alkyl = growing polymer). The activities found are the highest described so far for this alkenylnorbornene derivative. The catalytic species are generated from a palladium $\eta^{3}$-benzylic complex, $\left[\mathrm{Pd}(\mu-\mathrm{Br})\left(\eta^{3}\right.\right.$ $\left.\left.\mathrm{C}_{6} \mathrm{H}_{5} \mathrm{CHCH}_{2} \mathrm{C}_{6} \mathrm{~F}_{5}\right)\right]_{2}$ (1), which has proved to be an excellent precatalyst and does not need the addition of an alkyl donor (such as MAO or other organometallics). Moreover, no excess of ligands or a halide scavenger are required and just one equivalent of $\mathrm{PCY}_{3}$ and $\mathrm{NaBAr}_{4}{ }_{4}$ per palladium are necessary. The $\eta^{3}$-benzylic precursor provides an easy path for coordination of the monomer and insertion into the Pd-R bond due to the easy interconversion to the $\sigma$-benzylic coordination mode. Complex 1, $\mathrm{PC}_{3}, \mathrm{NaBAr}_{4}{ }_{4}$ and $\mathrm{VNB}$ can be mixed in any order leading to the same catalytic species and the same catalytic activity. However the initiation reaction of the neutral complex 1 with VNB involves a $\beta$-H elimination and insertion of the monomer into a $\mathrm{Pd}-\mathrm{H}$ bond. The subsequent addition of $\mathrm{PCy}_{3}$ and $\mathrm{NaBAr}_{4}$ generates the active cationic complex. In contrast, the reaction of VNB with a preformed cationic complex $\left[\mathrm{Pd}\left(\eta^{3}-\mathrm{C}_{6} \mathrm{H}_{5} \mathrm{CHCH}_{2} \mathrm{C}_{6} \mathrm{~F}_{5}\right)\left(\mathrm{PCY}_{3}\right) \mathrm{L}\right] \mathrm{BAr}_{4}{ }_{4}(\mathbf{3}, \mathbf{4})$ leads to insertion of $\mathrm{VNB}$ into the $\mathrm{Pd}-\mathrm{C}$ (benzyl) bond and the incorporation of the benzyl moiety in the polymer. This is a good example that shows how the cationic palladium species favor the 1,2-olefin insertion vs. a $\beta$-H elimination.

The vinylic addition polymerization of the readily available 5vinyl 2-norbornene gives interesting polymers with an aliphatic backbone and pendant terminal double bonds amenable to further functionalization leading to a variety of new polymers. However it has been a tough substituted norbornene to polymerize. The catalytic system described here allows to obtain VA-PVNB in high yields and high molecular weights with just $2 \mathrm{ppm}$ of $\mathrm{Pd}$.

\section{Conflicts of interest}

There are no conflicts to declare. 


\section{Acknowledgements}

We acknowledge the financial support of the Spanish MICINN (AEI PID2019-111406GB-I00) and the Junta de Castilla y LeónFEDER (grant VA224P20). We are also indebted to Dr. Marconi Peñas for his help with the X-ray crystal structure refinements.

\section{Notes and references}

1 F. Blank and C. Janiak, Coord. Chem. Rev., 2009, 253, 827-861.

2 M. V. Bermeshev and P. P. Chapala, Prog. Polym. Sci., 2018, 84, 1-46.

3 S. Martínez-Arranz, A. C. Albéniz and P. Espinet, Macromolecules, 2010, 43, 7482-7487.

4 R. García-Loma and A. C. Albéniz, Asian J. Org. Chem., 2019, 8, 304-315.

5 L. F. Rhodes, B. L. Goodall, R. Mülhaupt, R. A. Shick, G. M. Benedikt, S. K. Jayaraman, L. M. Soby, L. H. McIntosh III, US Pat. 6649707B1, 2003.

6 H. Li, J. Li, Y. Zhang and Y. Mu, Polymer, 2008, 49, 2839-2844.

7 B. Commarieu, J. Potier, M. Compaore, S. Dessureault, B. L. Goodall, X. Li and J. P. Claverie, Macromolecules, 2016, 49, 920925.

8 M.-J. Kim, H. Park, J. Ha, L. N. Thi Ho, E. C. Kim, W. Lee, S. Park, J. C. Won, D.-G. Kim, Y. H. Kim and Y. S. Kim, J. Mater. Chem. C, 2021, 9, 4742-4747.

9 F. Blank, H. Scherer and C. Janiak, J. Mol. Catal. A Chem., 2010, 330, 1-9.

10 J. K. Funk, C. E. Andes and A. Sen, Organometallics, 2004, 23, 1680-1683.

11 I. Takamiya, M. Yamashita and K. Nozaki, Organometallics, 2008, 27, 5347-5352.

12 J. Potier, B. Commarieu, A. Soldera and J. P. Claverie, ACS Catal., 2018, 8, 6047-6054.

13 E. V. Bermesheva, A. I. Wozniak, F. A. Andreyanov, G. O. Karpov, M. S. Nechaev, A. F. Asachenko, M. A. Topchiy, E. K. Melnikova, Y. V. Nelyubina, P. S. Gribanov and M. V. Bermeshev, ACS Catal., 2020, 10, 1663-1678.

14 A. H. Farquhar, M. Brookhart and A. J. M. Miller, Polym. Chem., 2020, 11, 2576-2584.

15 X.-W. Han, O. Daugulis and M. Brookhart, Organometallics, 2021, 40, 2709-2715.

16 T. Saito and Y. Wakatsuki, Polymer, 2012, 53, 308-315.

17 A. D. Hennis, J. D. Polley, G. S. Long, A. Sen, D. Yandulov, J. Lipian, G. M. Benedikt, L. F. Rhodes and J. Huffman, Organometallics, 2001, 20, 2802-2812.

18 F. Blank, J. K. Vieth, J. Ruiz, V. Rodríguez and C. Janiak, J. Organomet. Chem., 2011, 696, 473-487.

19 S. Marathe and S. Sivaram, Macromolecules, 1994, 27, 10831086.

20 H. Lasarov and T. T. Pakkanen, Macromol. Chem. Phys., 2000, 201, 1780-1786.

21 Y. Sarazin, G. Fink, K. Hauschild and M. Bochmann, Macromol. Rapid Commun., 2005, 26, 1208-1213.

22 B. Martín-Ruiz, I. Pérez-Ortega and A. C. Albéniz, Organometallics, 2018, 37, 1074-1085.
23 B. Martín-Ruiz, I. Pérez-Ortega and A. C. Albéniz, Organometallics, 2018, 37, 1665-1670.

24 M. D. Walter, R. A. Moorhouse, S. A. Urbin, P. S. White and M. Brookhart, J. Am. Chem. Soc., 2009, 131, 9055-9069.

25 M. D. Walter, P. S. White and M. Brookhart, Chem. Commun., 2009, 6361.

26 S. Sujith, E. K. Noh, B. Y. Lee and J. W. Han, J. Organomet. Chem., 2008, 693, 2171-2176.

27 H. C. Clark, A. B. Goel and S. Goel, Inorg. Chem., 1979, 18, 28032808.

28 F. Zaccaria, L. Sian, C. Zuccaccia and A. Macchioni, lon pairing in transition metal catalyzed olefin polymerization, Elsevier Inc., 1st edn., 2020, vol. 73.

29 L. Sian, A. Macchioni and C. Zuccaccia, ACS Catal., 2020, 10 1591-1606.

30 A. Macchioni, G. Bellachioma, G. Cardaci, M. Travaglia, C. Zuccaccia, B. Milani, G. Corso, E. Zangrando, G. Mestroni, C. Carfagna and M. Formica, Organometallics, 1999, 18, 30613069.

31 B. Binotti, G. Bellachioma, G. Cardaci, C. Carfagna, C. Zuccaccia and A. Macchioni, Chem. Eur. J., 2007, 13, 1570-1582.

32 D. I. Wozniak, W. A. Sabbers, K. C. Weerasiri, L. V. Dinh, J. L. Quenzer, A. J. Hicks and G. E. Dobereiner, Organometallics, $2018,37,2376-2385$ 